\title{
Programas de integridade como instrumento de boa governança pública: o FCPA e o U.K. Bribery como normas inspiradoras
}

\section{Integrity programs as an instrument of good public governance: $F C P A$ and $U . K$. Bribery as inspiring standards}

\author{
Claudio Carneiro Bezerra Pinto Coelho ${ }^{1}$ \\ Augusto Moutella Nepomuceno ${ }^{2}$
}

\begin{abstract}
RESUMO:
O Brasil, assim como ocorreu nos EUA na década de setenta, passa atualmente por um grave problema de corrupção institucionalizada que se entranhou em vários setores da esfera pública e privada. Diante desse quadro e do momento Constitucional que o país atravessa (Neoconstitucionalismo) buscou-se importar modelos bem-sucedidos nos EUA e na Europa, como por exemplo, as leis estrangeiras denominadas FCPA e o U.K. Bribery Act respectivamente, que serviram de referencial teórico. O objetivo do presente estudo é abordar a importância da implantação desses Programas de Integridade no Brasil como instrumento de Boa Governança Pública. Através do método científico indutivo se constata a necessidade de uma mudança comportamental em toda a sociedade para reconhecer que a Era da Integridade é necessária e urgente para o país.
\end{abstract}

\section{PALAVRAS-CHAVE:}

Programa de Integridade; Neoconstitucionalismo; Governança Pública

\begin{abstract}
:
Brazil, as it did in the US in the 1970s, is currently experiencing a serious problem of institutionalized corruption that has taken root in various sectors of the public and private sphere. Given this scenario and the Constitutional moment that the country is going through (Neoconstitutionalism), we sought to import successful models in the US and Europe, such as the foreign laws called FCPA and the U.K. Bribery Act respectively, which served as a theoretical reference. The aim of this study is to address the importance of implementing these Integrity Programs in Brazil as an instrument of Good Public Governance. Through the inductive scientific method, one realizes the need for behavioral change throughout society to recognize that the Age of Integrity is necessary and urgent for the country.
\end{abstract}

\section{KEYWORDS:}

Integrity Program; Neoconstitucionalism; Public governance.

\footnotetext{
${ }^{1}$ Advogado, Consultor e Auditor de Compliance. Pós-Doutor pela Universidade Nova de Lisboa (Portugal). Doutor em Direito Público e Evolução Social. Mestre em Direito Tributário. Vice-presidente da Ethical \& Compliance International Institute. Coordenador dos Cursos de Compliance Avançado e Planejamento Tributário da Fundação Getúlio Vargas (FGV). Professor dos Cursos de Mestrado e Doutorado da Universidade Autónoma de Lisboa (UAL). Professor do Curso de Mestrado da UniFG/BA.

${ }^{2}$ Mestre em direito (UCAM). Especialista em direito (UGF). Gestor Nacional dos Cursos de Direito - Estácio. Professor Universitário em Direito Administrativo (UNESA - Graduação em direito e Pós-graduação latu sensu em direito público).
} 


\section{INTRODUÇÃO}

Infelizmente, percebemos ao longo dos últimos anos que a corrupção contaminou o mundo moderno e, especialmente o Brasil. Diante desse cenário crítico não é possível ficar inerte e esperar o tempo passar para ver se o fenômeno da corrupção se extingue por si só. Ao contrário, faz-se necessário o investimento em rígidos programas de integridade, de combate à corrupção e ao suborno e, da mesma forma, exigir uma mudança comportamental por parte das empresas privadas e, prioritariamente, do Poder Público. Nesse sentido, com amparo na Constituição democrática e republicana de 1988, deve-se investir na aplicação das normas existentes, na criação de normas rígidas e na implantação de sistemas de gestão que exteriorizam a transparência necessária para a boa governança pública, de modo a mitigar e, até mesmo, evitar os atos de corrupção e de má gestão.

O gerenciamento de riscos, a implantação e monitoramento de Programas de Integridade são as bases para a edição das normas afetas à integridade pública e privada, como por exemplo, as leis 13.303/16 (Lei das Estatais) e 12.846/13 (Lei Anticorrupção).

A concepção de Boa Governança, nos dias atuais, deve ser tratada como verdadeiro direito fundamental, e não como mera recomendação ao administrador, pois o mau governo, seja por escolhas indevidas por seus administradores ou simplesmente por atos de corrupção ou suborno, acabam por comprometer direitos assegurados em nossa Constituição Federal e, com isso, caminhar na contramão da evolução do (Neo)constitucionalismo.

A influência de leis estrangeiras é cada vez mais forte no Brasil e o Compliance (integridade), que traz em sua essência normas de Boa Governança, Gestão de Riscos e combate à corrupção e ao suborno, pode ser considerado um importante instrumento para o avanço do movimento constitucionalista no país. Isto porque busca ampliar os instrumentos de controle e conferir uma maior transparência da gestão dos recursos públicos e, com isso, aumentar a efetividade dos direitos fundamentais, em especial os sociais que exigem um maior dispêndio de recursos. 
Igualmente pode-se afirmar, que tais direitos fundamentais denominados de direitos de $2^{\circ}$ Geração, guardam consigo uma atuação positiva do Estado e demandam uma análise acerca da finalidade almejada de nossa Carta Magna em conjunto com a efetividade das normas nela estatuída, o que oportuniza a abertura de novas alternativas com o escopo de desenvolver a atividade do administrador público e reestruturar a máquina de forma a lhe atribuir uma maior produtividade e eficácia aliada ao acréscimo da participação do indivíduo.

Logo, haverá uma redução da desigualdade e longitude anteriormente presentes na relação cidadão-governo, para caminhar na direção de uma boa governança que poderá usufruir destes instrumentos de controle para seu aprimoramento e continuidade.

Assim, a nefasta e frequente alegação de escassez de recursos torna imprescindível que se dê um destino cada vez mais responsável ao orçamento disponível, revelando-se absolutamente incompatível com a ordem de direitos trazida pela Constituição, a má governança ou uma gestão imoral ou improba. Para tanto, a implantação de um Programa de Integridade é um forte instrumento para uma Boa Governança rumo à efetividade constitucional e transparência administrativa, elementos intrínsecos às diretrizes de todo Programa de Integridade.

\section{A IMPORTÂNCIA DO (NEO)CONSTITUCIONALISMO NAS POLÍTICAS DE INTEGRIDADE}

Em diversos países da Europa, como por exemplo, Itália, Alemanha, Portugal e Espanha, as Constituições marcaram a ruptura com o autoritarismo, estabelecendo um compromisso com a paz, especialmente no que se refere ao desenvolvimento e respeito aos Direitos Fundamentais e, numa visão mais ampla os Direitos Humanos. 
Por influência do direito estrangeiro, o grande marco do Constitucionalismo Contemporâneo ${ }^{3}$ no Brasil foi a abertura democrática vivida em meados da década de 1980 e a elaboração da Constituição da República de 1988.

A dignidade da pessoa humana passou a ser um dos elementos essenciais desse movimento constitucionalista, devendo ser assegurado pelos Poderes Públicos e pela própria sociedade. Nesse sentido também, o enaltecimento da força normativa da Constituição, pois nà luz de uma análise econômica, direitos custam dinheiro ${ }^{4}$. Para CARBONELL e JARAMILO ${ }^{5}$, as constituições europeias citadas contêm amplos catálogos de direitos fundamentais: “... lo que viene a suponer um marco muy renovado de relaciones entre el Estado y los ciudadanos, sobre todo por la profundidad y el grado de detalle de los postulados constitucionales que recongen tales derecho".

Autores brasileiros divergem sobre o chamado Neoconstitucionalismo. Segundo SARMENTO $^{6}$, envolve fenômenos como a força normativa dos princípios, a rejeição do formalismo, a reaproximação entre o Direito e a Moral e a judicialização da Política.

Para $\mathrm{BARROSO}^{7}$, são características do Neoconstitucionalismo a redescoberta dos princípios jurídicos (em especial a dignidade da pessoa humana), a expansão da jurisdição constitucional, com ênfase no surgimento de tribunais constitucionais, e o desenvolvimento de novos métodos e princípios na hermenêutica constitucional.

Já na visão de $\mathrm{STRECK}^{8}$, o Neoconstitucionalismo significa ruptura, tanto com o Positivismo como no modelo de Constitucionalismo Liberal. Em razão desse motivo, o Direito deixaria de ser regulador para ser transformador. Para este autor há uma incompatibilidade

\footnotetext{
${ }^{3}$ Preferimos usar a expressão Constitucionalismo Contemporâneo em detrimento de Neoconstitucionalismo. A justificativa para tal pode ser melhor observada em nossa obra: CARNEIRO, Claudio. Neoconstitucionalismo e Austeridade Fiscal: confronto constitucional-hermenêutico das cortes constitucionais do Brasil e de Portugal. Salvador: Juspodivm. 2017.

${ }^{4}$ SUNSTEIN, Cass; HOLMES, Stephen. The cost of rights: why liberty depends on taxes. Nova Iorque: W.W. Norton \& Company, 1999. P 15.

${ }^{5}$ CARBONELL, Miguel e JARAMILLO, Leonardo Garcia. El Canon Neoconstitucional. Madri: Editora Trota. 2010. P. 154.

${ }^{6}$ SARMENTO, Daniel. Filosofia e Teoria Constitucional Contemporânea. Rio de Janeiro: Lumen Juris, 2009. P. 113.

${ }^{7}$ BARROSO, Luiz Roberto. Interpretação e Aplicação da Constituição, São Paulo: Renovar, 2013. P.48.

8 STRECK, Lenio Luiz. Verdade e Consenso. Constituição Hermenêutica e Teorias Discursivas. Da possibilidade à necessidade de respostas corretas em Direito. Rio de Janeiro: Lumen Juris. 2009. P 8.
} 
paradigmática entre o novo Constitucionalismo (compromissório, principiológico e dirigente) e o Positivismo Jurídico, nas suas mais variadas formas, e nesse sentido, qualquer postura que, de algum modo, se enquadre nas características ou teses que sustentam o Positivismo, entraria na linha de colisão com esse (novo) tipo de constitucionalismo?.

Apesar das divergências sobre o referido movimento constitucional, há que se considerar que a Constituição de 1988 sofre algumas críticas por parte da doutrina ${ }^{10}$ e aqui, para sermos sucintos, citaremos apenas duas. A primeira é o detalhismo de assuntos que não mereciam estar em um texto Constitucional. A segunda diz respeito a alguns itens considerados inalcançáveis ou utópicos, inferindo que a Assembleia Constituinte, em alguns momentos, se afastou, sobremaneira, do mundo dos fatos, ou seja, estabelecendo diretrizes intangíveis ou irrealizáveis.

Apesar de o artigo 37 da Constituição de 1988 trazer princípios adstritos à Administração Pública, a integridade na concepção de transparência passa a integrar o consolidado rol de princípios constitucionais mencionados. Exatamente por isso que se deve abordar o Programa de Integridade e a Boa Governança Pública à luz da Constituição de 1988 e, obviamente, interpretá-la com base no momento constitucional em que ela se encontra, isto é, o Constitucionalismo Contemporâneo. Ignorar o momento constitucional atual assemelha-se a determinar a confecção de uma vestimenta nova cujo modelo foi sucesso em décadas passadas.

\subsection{Aspectos históricos e normativos relevantes no Brasil e no mundo}

A evolução internacional ocorreu ao longo das décadas, mas o embrião sobre Compliance teve sua origem nos EUA. Em 1906, com a promulgação do Food and Drug Act, o governo norte-americano criou um modelo de fiscalização centralizado como forma de regular as atividades relacionadas à saúde alimentar e ao comércio de medicamentos, contudo, foi devido às instituições financeiras que o compliance avançou.

\footnotetext{
${ }^{9}$ STRECK, Lenio Luiz. Jurisdição Constitucional e Hermenêutica. Uma nova crítica do direito. 2 ed. Rio de Janeiro: Forense. 2014. P.3.

${ }^{10}$ BARROSO, Luiz Roberto. Op. Cit. P. 47.
} 
Alguns fatos históricos relevantes contribuíram para a criação e o amadurecimento de diversas normas ao longo de décadas. Dessa forma, conhecer a legislação internacional e a sequência cronológica de fatos relevantes mostra-se imprescindível para a implementação de Programas de Compliance de alto nível.

À título de ilustração, podemos citar alguns momentos importante ao longo da história: em 1913 foi criado do Banco Central Americano (Board of Governors of the Federal Reserve) para implementar um sistema financeiro mais flexível, seguro e estável; no ano de 1945, por meio das Conferências de Bretton Woods foi criado o Fundo Monetário Internacional (FMI) e o Banco Internacional para Reconstrução e Desenvolvimento(BIRD), com o objetivo básico de zelar pela estabilidade do Sistema Monetário Internacional; em 1960 a SEC passa a insistir na contratação de Compliance Officers para criar procedimentos internos de controles, treinar e monitorar pessoas com o objetivo de auxiliar as áreas de negócios a ter a efetiva supervisão; em 1988 foi estabelecido o primeiro Acordo de Capital da Basiléia, definindo padrões para a determinação do capital mínimo das instituições financeiras, em 1998 foi publicada no Brasil a Lei n. 9.613, a qual dispôs sobre crimes de lavagem ou ocultação de bens, a prevenção da utilização do Sistema Financeiro Nacional para atos ilícitos previstos em seu texto e instituiu o Conselho de Controle de Atividades Financeiras (COAF); e no ano de 1999 destacamos a criação do Eastern and Southern Africa Anti-Money Laundering Group.

O cenário que se passava em outros países também avançava no Brasil e após a aprovação do Decreto Legislativo n. 125/00, foi editado o Decreto n. 3.678 no mesmo ano, que internalizou a Convenção sobre o Combate da Corrupção de Funcionários Públicos Estrangeiros em Transações Comerciais Internacionais, tomando como base na versão revisada da OCDE (Paris, 17.12.1997). Ato contínuo, em 2002 foi editado no Brasil o Decreto n. 4.410 que promulgou a Convenção Interamericana contra a Corrupção, após sua aprovação pelo Congresso Nacional por meio do Decreto Legislativo n. 152/02.

A sobredita Convenção tinha o objetivo de promover o desenvolvimento dos mecanismos necessários para prevenir, detectar, punir e erradicar a corrupção e, ainda, disseminar a cooperação entre os Estados-partes a fim de assegurar a eficácia das medidas e 
ações adotadas para o combate à corrupção pública, bem como os atos especificamente vinculados ao seu exercício ${ }^{11}$.

Em 2002, a falha nos Controles Internos e a ocorrência de fraudes contábeis levaram à concordata da WORLDCOM. Ato contínuo, o Congresso Americano publica a famosa "Sarbanes-Oxley Act", que determinou às empresas registradas na SEC a adoção das melhores práticas contábeis, independência da Auditoria e criação do Comitê de Auditoria. Em 2006 foi editado o Decreto n. 5.687 que promulgou a Convenção das Nações Unidas contra a Corrupção, adotada pela Assembleia Geral das Nações Unidas (em 31.10.2003 e assinada pelo Brasil em 09.12.2003). O texto aprovado pelo Decreto Legislativo n. 348/2005 tinha como objetivo promover e fortalecer as medidas para prevenir e combater a corrupção; promover a cooperação internacional e a assistência técnica na luta contra a corrupção e na recuperação de ativos; bem como promover a integridade na gestão pública.

No ano de 2013, o Brasil, alinhado a uma tendência mundial de enfrentamento da corrupção, promulgou sua Lei Anticorrupção (Lei n. 12.846/13), seguida do seu decreto regulamentador (Decreto n. 8.420/15) e, posteriormente, a Lei n. 13.303/16 que tratou do chamado Compliance Público.

Por fim, vale lembrar que o rol apresentado é exemplificativo e muitos outros diplomas legais foram editados no Brasil e no mundo. Em 2018, por exemplo, foram publicadas diversas Portarias Conjuntas no Brasil, entre elas a que define os procedimentos de troca de dados e informações entre a Corregedoria-Geral da União do Ministério da Transparência e Controladoria-Geral da União e o Conselho Administrativo de Defesa Econômica, para a apuração de casos envolvendo o suborno transnacional, de que trata o artigo $9^{\circ}$, da Lei $n^{\circ}$ $12.846 / 13$.

Por todo o exposto até agora, é possível concluir que o Brasil está em um caminho sem volta na Era do Compliance ${ }^{12}$. Apesar de os EUA terem começado na década de setenta e, por

\footnotetext{
${ }^{11}$ PESTANA, Marcio. Lei Anticorrupção: Exame Sistematizado da Lei n. 12.846/13. São Paulo: Manoel. 2016. P. 8 e 9.

12 Nesse contexto, também foram editadas as seguintes normas: a) Código de Ética Profissional do Servidor Público Civil do Poder Executivo Federal (Decreto 1.171, de 22 de Junho de 1994); b) Lei de Responsabilidade Fiscal (Lei Complementar 101, de 4 de maio de 2000); c) Programa Nacional de Gestão Pública e Desburocratização (GesPública), instituído em 2005; d) Lei no 12.527, de 18 de novembro de 2011, chamada de Lei do Acesso a Informação; e) Lei no 12.813, de 16 de maio de 2013, chamada de Lei de Conflito de Interesses
} 
isso, já contarem com uma estrutura mais sedimentada que a nossa, a base jurídica e doutrinária brasileira começa a se consolidar, o que de maneira alguma nos impede de alcançarmos níveis de excelência, até porque podemos mesclar o que de melhor há em cada país e adaptá-las.

\subsection{Importantes leis estrangeiras: FCPA e U. K. BRIBERY ACT}

O FCPA (norma estadunidense) e o U.K. Bribery (norma do Reino Unido) foram uns dos principais diplomas legais que serviram de modelo para a edição das normas de combate à corrupção no Brasil.

O Foreign Corrupt Practices Act (FCPA) é uma lei federal americana, de 1977, que visa combater a corrupção e o suborno. Por outro lado, a Bribery Act, nasceu na Inglaterra e entrou em vigor dia $1^{\circ}$ de Julho de 2011, sendo considerada uma das legislações mais rígidas do mundo sobre o tema.

O FCPA nasceu com o objetivo de combater o suborno de funcionários públicos estrangeiros e, com isso, buscar garantir ${ }^{13}$ a integridade do mercado de capitais dos EUA, tanto quanto devolver a confiança da sociedade no sistema corporativo daquele país. A lei americana dispõe de uma característica pouco mencionada, mas que a diferencia, essencialmente, de outros diplomas. Isto porque, o FCPA responsabiliza a corrupção ativa, ou seja, preocupa-se com o ato do corruptor, não trazendo, em seu bojo normativo, consequências para a corrupção passiva.

Quanto à competência e sua aplicabilidade, o referido diploma alcança qualquer cidadão americano, subsidiária americana ou estrangeira (inclusive brasileira) em solo americano que tenha capital americano e empresas estrangeiras que tenham negócios ou conexões com os EUA, além de outras situações específicas.

\footnotetext{
no exercício de cargo ou emprego do Poder Executivo Federal; f) Lei n. ${ }^{\circ} 12.846$ de $1^{\circ}$ de agosto de 2013, intitulada Lei Anticorrupção, com seu respectivo Decreto regulamentador de n 8.420 de 18 de março de 2015 e; g) Decreto 8.793 de 29 de junho de 2016 que institui a Política Nacional de Inteligência. Vale ressaltar que o rol não é exaustivo, pois dispositivos de outros diplomas também devem ser invocados para compor todo o ordenamento pertinente à matéria.

${ }^{13}$ STELLMACH, William. Foreign Corrupt Practices Act. Disponível em: http://www.justice.gov/criminal/fra ud/fcpa/ - Acesso em: 13 de junho de 2018.
} 
Vale ressaltar que a eficácia de uma norma americana sobre empresas brasileiras (com sede no nosso país), poderia ser considerada algo aviltante para o Brasil, face ao princípio da territorialidade e da soberania nacional, pois em tese não estaria submetida à jurisdição americana. Contudo, se uma empresa brasileira exporta mercadorias para os EUA, mas de forma ilegal, tal fato, por si só, já a enquadra como violadora da FCPA e poderá sofres as sanções nela prevista. Com base nesse exemplo, é possível afirmar que a aplicabilidade da FCPA no Brasil é real, valendo para empresas brasileiras com negócios, subsidiárias ou listadas na bolsa de valores americana; para organizações brasileiras que prestem serviços a organizações americanas, como representante ou agente; empresas e indivíduos brasileiros que efetuem, diretamente ou por meio de intermediários, um pagamento indevido em solo americano ou que por lá transite; e as holdings americanas são responsáveis pelos atos das suas subsidiárias brasileiras enquanto tenham autorizado, dirigido ou controlado suas atividades.

O FCPA prevê sanções cíveis e criminais e, nesse sentido, as Organizações podem receber multas elevadas, sofrer sanções administrativas e, sobretudo, sofre um grave dano reputacional (mídia negativa, dano à imagem, dissolução da empresa). Já para os indivíduos, as sanções podem ser o pagamento de multa, prisão e dano reputacional. Com o objetivo de promover a responsabilização e aplicação do FCPA, existem dois órgãos de atuação: Securities Exchange Commission (SEC) e o Department of Justice (DOJ). Enquanto o DOJ possui competência civil e criminal para investigar e deflagrar ações penais (criminal law enforcement), relativamente às violações do FCPA, a SEC detém competência civil e administrativa (civil law enforcement).

Em apertada síntese, podemos dizer que o FCA possui, entre outras, as seguintes atribuições: a) investigar pessoas físicas ou jurídicas; b) regulação das condutas relacionadas à comercialização de produtos financeiros; e c) determinar que as empresas retirem imediatamente promoções enganosas e que publiquem tais decisões.

Outro diploma de grande importância para nosso estudo, diz respeito ao United Kingdom Bribery Act ou, comumente chamado, de U.K. Bribery de origem no Reino Unido de combate à corrupção internacional editada no ano de 2010.

Partindo para a Bribery Act, percebe-se que esta legislação, no que se refere a local e extraterritorialidade, engloba empresas do Reino Unido que fazem negócio local e no exterior, 
empresas estrangeiras com operações no Reino Unido, funcionários públicos locais e estrangeiros e o setor público e privado de modo geral.

Vale ressaltar que o Reino Unido foi bastante criticado por suas práticas negociais. A uma pela possibilidade de dedução no imposto de renda da propina ofertada em outros países (com empresas ou governos estrangeiros) à semelhança do que previa a legislação alemã. A duas pela demora na edição de uma lei de combate à corrupção. Diante desse cenário, o governo Britânico editou o Bribery Act com o objetivo de dar uma resposta social às críticas pela inércia legislativa no combate da corrupção. Talvez esses elementos tenham sido o motivo para a edição da mais rígida lei antissuborno em vigor, justamente por contar com dispositivos que carregam pesadas sanções, moduladas de forma mais gravosa que os demais diplomas anticorrupção.

O papel que é desempenhado pelo SEC (Security Exchange Commission) nos EUA, no Reino Unido é executado pelo SFO (Serious Fraud Office) que possui atribuição de investigar e responsabilizar atos de corrupção, com atuação na Inglaterra, País de Gales e Irlanda. Considerado um órgão independente e rigoroso, o SFO está vinculado diretamente à Procuradoria Geral do Reino Unido, podendo requerer a qualquer pessoa, sejam elas físicas ou jurídicas, que forneçam documentos relevantes, inclusive sigilosos, ou que respondam perguntas sobre quaisquer assuntos relevantes, confidenciais ou não, para o caso analisado.

As sanções são cíveis ou criminais, podendo ser penalizadas tanto a pessoa física quanto a jurídica. Para as empresas as multas são ilimitadas, enquanto para os indivíduos as multas são limitadas, e pode ser aplicada também pena de até dez anos de prisão. Os diretores podem ser penalizados com a destituição do cargo e proibição de atuar como diretor por até quinze anos; se for algum contratante público é possível a sua exclusão de tais contratos. A lei também prevê danos reputacionais (mídia negativa, dano à imagem, dissolução da empresa).

Para a Bribery Act, as seguintes ações do indivíduo ou empresa geram responsabilidade: oferecer, prometer, pagar, requerer, concordar em receber ou aceitar vantagem, subornar oficial estrangeiro e falhar na prevenção de corrupção. O objeto pode ser dinheiro ou qualquer vantagem, financeira ou não e quanto ao objetivo não é necessário ter o intuito de corromper. Para o diploma em comento, quem se quer corromper deverá ser oficial público estrangeiro ou âmbito privado, utilizando o meio direto ou indireto, sendo que o 
entendimento é abrangente (pessoas associadas, empregados, terceiros, intermediários como agentes ou subsidiários), com a finalidade de manter ou obter vantagem na condução do negócio.

Por fim, enquanto o FCPA se subdivide em duas partes, o UKBA prescreve quatro categorias de infrações distintas: a) o ato de oferecer vantagem indevida; b) o ato de aceitar vantagem indevida; c) o suborno de funcionário público estrangeiro; e d) a falha na prevenção de corrupção por uma pessoa jurídica.

Valendo-se de experiências adquiridas em outros países ou até mesmo idealizadas no Brasil, o fato é que as fraudes passaram por extraordinária modificação e sofisticação. Se antes era praticado por um processo isolado e individual de um agente, hoje, a questão transformou em complexos esquemas dotados de tecnicidade, que somente podem ser combatidos com uma tecnologia da informação e dos meios eletrônicos mais modernos ${ }^{14}$.

As crises econômicas são fatores relevantes para equilíbrio econômico-financeiro das empresas. Dessa forma, para superar uma crise ou, simplesmente, estabilizar o cenário financeiro de uma empresa, um bom Programa de Compliance é fundamental, pois é capaz de identificar divergências entre o que se paga e o que deveria ser pago, adequando a Organização antes que a mesma sofra sanções administrativas, judiciais e pecuniárias, pois talvez ela possa pagar a diferença de tributos e continuar normalmente a sua operação, mas uma multa acabaria com o seu caixa, levando-a a falência.

Muitas fraudes cometidas pelas Organizações perpassam por fraudes fiscais ${ }^{15}$, seja para criar sistemas de caixa dois para dar lastro financeiro paralelo para encobrir os esquemas de corrupção ou para sonegar tributos.

Por isso, evitar a ocorrência de fraudes e agir corretamente com obrigações fiscais é essencial para o crescimento das Organizações, já que as Receitas (nas três esferas de governo)

\footnotetext{
${ }^{14}$ SOARES, Inaldo de Vasconcelos. Fraudes nas Gestões Públicas e Privadas. Brasília: Brasilia Jurídica. 2005. P; 53.

${ }^{15}$ Sobre questões tributárias e fiscais, recomendamos as obras: CARNEIRO, Claudio. Curso de Direito Tributário e Financeiro. 7ed. São Paulo: Saraiva. 2018; CARNEIRO, Claudio. Processo Tributário (Administrativo e Judicial). 5ed. São Paulo: Saraiva. 2018; CARNEIRO, Claudio. Impostos Federais, Estaduais e Municipais. 6ed. São Paulo: Saraiva. 2018.
} 
ao imputar multas fiscais severas podem acarretar a quebra da empresa e gerar cometimento de crimes.

Por isso, o canal de denúncias é classificado como um dos pilares de um Programa de Compliance e, atualmente, por força dos contratos e exigências realizadas por organizações transnacionais em todo o mundo, sua implantação se tornou uma realidade necessária.

\section{BOA GOVERNANÇA NO SETOR PUBLICO E A IMPORTÂNCIA DO PROGRAMA DE INTEGRIDADE COMO FERRAMENTA DE EFETIVIDADE TRANSPARÊNCIA}

Ao longo de décadas presenciamos escândalos que culminaram com diversas formas, mas em todos eles o dinheiro público foi o principal alvo. A História mundial fez com que diversos países passassem a se preocupar com aspectos relacionados à governança. Nesse contexto, várias Organizações Internacionais entraram em cena com o objetivo de promover a Boa Governança, como por exemplo, o Banco Mundial e o Fundo Monetário Internacional (FMI).

No Brasil, ainda que tardiamente, o interesse pelo tema surgiu com mais intensidade sobre o setor privado. Contudo, percebe-se que o interesse pela Governança Corporativa tinha que partir do próprio setor público onde foram detectados diversos “ralos de corrupção". Dessa forma, tanto no setor público quanto no privado, passaram e existir iniciativas de melhoria da governança.

Assim, a ideia de governança pública originou-se da governança corporativa (corporate governance). Segundo a Organização para Cooperação e Desenvolvimento Econômico, a governança corporativa é definida como o conjunto de relações entre a administração de uma empresa, seu Conselho de Administração, seus acionistas e outras partes interessadas. Significa dizer que é um conjunto de práticas que têm por objetivo regular a administração e o controle das instituições. O Instituto Brasileiro de Governança Corporativa (IBGC) define Governança Corporativa como "o sistema pelo qual as organizações são 
dirigidas, monitoradas e incentivadas, envolvendo os relacionamentos entre proprietários, conselho de administração, diretoria e órgãos de controle”. Conclui o IBCG que as boas práticas de governança corporativa “convertem princípios em recomendações objetivas, alinhando interesses com a finalidade de preservar e otimizar o valor da organização, facilitando seu acesso a capital e contribuindo para a sua longevidade”.

A legislação brasileira trouxe como um de seus pilares, normas sobre a Boa Governança por parte da Administração Pública em todas as esferas de Governo (Federal, Estadual e Municipal). Como já visto, a expressão Governança deriva do termo Governo, e pode ter várias interpretações, dependendo do enfoque que lhe é dado. Dessa forma, deixamos consignado, desde já, que adotamos o contexto de Governança, como observância das normas de boa conduta para a Administração Pública, bem como o respeito às medidas adotadas pelas leis para governar o país em questão dentro de uma política ética e de combate à corrupção, ao suborno e às irregularidades administrativas. Entre as principais características para se alcançar a ideia de boa governança podemos citar, como exemplo, a transparência, a integridade, a equidade, a responsabilidade dos gestores e da alta administração e, sobretudo, a transparência e a prestação de contas.

Em apertada síntese, podemos afirmar que Governança no Setor Público diz respeito a um conjunto de mecanismos práticos de controle que envolvem temas afetos à liderança, estratégia e informação com o objetivo de executar as quatro etapas: a) identificar as questões sensíveis; b) tratar as dados (informações) obtidos; c) redimensionar o sistema corrigindo as falhas e implementando os modelos pendentes; d) monitoramento periódico.

As quatro fases elencadas visam à adequação dos instrumentos para a concretização de políticas públicas e à prestação de serviços de interesse da sociedade. Percebe-se, então, que a governança no setor público deve ser analisada sob algumas perspectivas que otimizarão o campo de observação e que vão proporcionar a eficácia no cumprimento das etapas a serem seguidas: a) a sociedade (destinatário) e Estado (agente); b) federalização - A implementação do Compliance Público carece ser adaptado de acordo com a realidade dos entes federativos; c) órgãos estruturantes e entidades envolvidas no processo de gestão.

Nessa toada, o Brasil vem editando importantes diplomas normativos, entres eles a lei anticorrupção e a lei das estatais. A primeira direciona-se à iniciativa privada e a segunda refere- 
se às empresas públicas e sociedades de economias mista. A lei n. 13.303/16, também chamada de Estatuto das Estatais (parágrafo quarto do seu artigo nono), traz uma única vez em seu texto a expressão Compliance (integridade) ao determinar que o estatuto social deverá prever a possibilidade de que a área de Compliance se reporte diretamente ao Conselho de Administração em situações que haja suspeita do envolvimento do diretor-presidente em irregularidades ou quando este descumprir a obrigação de adotar medidas necessárias em relação à situação a ele relatada.

Atente-se que neste aspecto a Lei das Estatais caminhou no sentido de atribuir uma independência a esta área com intuito de desestimular possíveis comportamentos corruptivos e incentivar aplicação de políticas de integridade dentro das instituições. O Decreto n. 8.945/2016, regulamentador desta Lei, dedicou-se às normas sobre governança das estatais, regulamentando o exercício da atividade fiscalizatória pelo Estado e pela sociedade.

A Lei Anticorrupção, a Lei das Empresas Estatais e tantos outros diplomas importantes, criaram um microssistema anticorrupção, o qual caminha para a incorporação no público e no privado de normas que permitam a prevenção da corrupção e estimulem a criação de uma cultura de integridade, isto é, uma geração que tenha como meta a eficiência do aparelhamento público e privado e, consequentemente, permita uma transparência de seus gastos e objetivos almejados. Vale lembrar que as empresas públicas, sociedades de economia mista e suas subsidiárias, apesar de serem classificadas com estatais, são pessoas jurídicas de direito privado. Dessa forma, em virtude do disposto no artigo 173 da Constituição da República de 1988, todas as entidades privadas que explorem atividade econômica devem ter o mesmo tratamento e, por isso, as estatais com muito mais razão devem estar inseridas nas práticas de Integridade.

Neste cenário, surge uma importante ferramenta que se propõe a dar efetividade e transparência às práticas anticorrupção, qual seja, o denominado e-government, ou governo eletrônico. A citada ferramenta hodiernamente utilizada pela Administração Pública interna e externa, é relevante e se destaca como meio de capacitação e redução da esfera de discricionariedade do administrador público, como também permite uma organização estrutural das relações que a Administração Pública estabelece com os seus administrados. 
Por conseguinte, tal meio torna-se plenamente aplicável ao Compliance Público dado que alicerçará os princípios constitucionalmente insculpidos e delimitados à Administração Pública para que funcionem em conjunto, buscando uma boa governança e privilegiando a Constituição da República, dado que passa a atribuir um maior prestígio aos princípios (normas de valor) renovando a denominada Teoria das Fontes e assumindo o desenvolvimento da teoria dos direitos fundamentais.

É importante dizer que alguns desafios serão encontrados pelo gestor público quando da implementação deste tipo de governo, já que, por se tratar de uma inovação, demandará uma reestruturação do modus operandi em conjunto com uma releitura do modelo cultural adotado pelos administrados.

No tocante a esta conjuntura principiológica, é pertinente recordar as gerações dos direitos fundamentais, mais especificamente, os direitos de segunda geração que podem ser qualificados como direitos fundamentais do indivíduo ${ }^{16}$ demandando do Estado uma atuação positiva, ou seja, impõe a intervenção deste no sentido de garantir a efetividade de sua atuação e a ordem social, protegendo a liberdade do homem integralmente e transcendendo sua individualidade com a finalidade de alcançar um caráter econômico e social para a devida justiça social.

Passa-se então, a se exigir uma otimização da Administração Pública para prestação dos serviços públicos como forma de garantia de qualidade e maior eficácia, o que importa em dizer que o Estado deverá buscar a utilização da tecnologia e de métodos adotados para alcançar a qualidade total quando da execução das atividades de sua responsabilidade.

Assim, é possível concluirmos que a eficiência administrativa está ligada ao fito de neutralidade, devendo o Estado valorar de forma igualitária todos seus administrados, utilizando-se para tal dos novos meios tecnológicos, pois estes tornam-se um instrumento de

\footnotetext{
16 Declaração Universal dos Direitos Humanos: “Art.25 1. Todo ser humano tem direito a um padrão de vida capaz de assegurar a si e à sua família saúde, bem-estar, inclusive alimentação, vestuário, habitação, cuidados médicos e os serviços sociais indispensáveis e direito à segurança em caso de desemprego, doença invalidez, viuvez, velhice ou outros casos de perda dos meios de subsistência em circunstâncias fora de seu controle." Disponível em: https://www.unicef.org/brazil/pt/resources_10133.htm. Acesso em: 25 de janeiro de 2019.
} 
transparência administrativa e vinculação da Administração, prezando por uma sociedade uniforme no que tange aos direitos e oportunidades.

Não remanescem dúvidas acerca da importância na utilização das novas tecnologias para garantia do direito à informação e transparência, incitando um contexto de surgimento do chamado e-government, ou governo eletrônico, reconhecido como uma infraestrutura multifuncional entre os diferentes órgãos públicos e utilizando-se de forma intensiva da tecnologia da informação para aprimorar o controle público e o atendimento ao cidadão.

No que se refere à sua implementação e continuidade, considera-se a existência de um custo para esse fim, o qual poderá ser mitigado diante da utilização de programas de integridade que transformem esse contexto propício à boa governança que se propõe nos ordenamentos supramencionados, privilegiando os princípios constitucionalmente insculpidos no artigo 37, da Carta da República, em particular, a eficiência, transparência e impessoalidade do gestor.

Para mais, ante a iminente necessidade de apurar e coibir os atos de corrupção, este mecanismo potencializa e consolida uma sistemática que dá maior ênfase a transparência pública no combate à corrupção e torna a prestação jurisdicional mais eficaz no que toca ao aspecto político e socioeconômico. Portanto, levando-se em consideração os diversos aspectos delineados, deve-se observar que os programas de integridade precisarão estar engajados com as políticas e boas práticas da Administração Pública, funcionando de maneira harmônica a garantir sua efetividade e transparência, características inerentes a quaisquer programas de integridade.

\section{CONCLUSÃO}

A concepção de Boa Governança Pública perpassa por vários aspectos, contudo, enfatizamos em nosso texto apenas um deles: a obrigatoriedade do uso eficiente do dinheiro público utilizando-se de experiências bem-sucedidas em outros países, como por exemplo, o Sistema de Gestão de Compliance e Antissuborno (também chamado de Programas de Integridade) e as tecnologias da informação. A ausência de corrupção e de suborno parece ser 
o óbvio e o correto, no entanto, apesar de sê-la de fato, nosso país, culturalmente, demanda de leis para prevenção e punição aos maus gestores, exigindo uma efetiva mudança comportamental na esfera pública e privada.

É nesse contexto que passa a ser aplicado no Brasil um rígido sistema de combate à corrupção e a implantação de modelos de integridade vividos em outros países, em especial o estadunidense. Contudo, há que se observar que um programa de integridade, para ser efetivo, deve pautar-se minimamente em duas bases de sustentação. A primeira diz respeito à utilização de um sistema de gestão anticorrupção, que não tem a ver apenas com diplomas legais ou aspectos jurídicos, mas com estruturas e ferramentas gerenciais customizadas em relação ao escopo da organização. A segunda está atrelada ao ordenamento jurídico nacional e internacional e, sobretudo, com o texto constitucional pátrio. Assim, de acordo com esse segundo pilar, deve-se ter em mente a importância da identificação do momento constitucional em que vivemos hoje, isto é, o Constitucionalismo Contemporâneo, pois a Constituição não é uma mera folha de papel, permitindo-se sua interação com outros ramos do Direito.

Dito de outra forma, ao se falar de integridade é importante interpretar as leis e as próprias normas constitucionais com um contexto amplo de constitucionalidade, ou seja, utilizando-se a hermenêutica constitucional sob a perspectiva do método sistemático, prevalecendo o conteúdo sobre a forma, os fins a que se destinam e o ideal a ser alcançado, analisando-se a CRFB/88 de modo amplo e a concatenar os institutos para que seja possível vislumbrar esta Carta Magna com dispositivos correlacionados a mesma temática.

Ante a classificação quanto à finalidade da nossa Constituição, denota-se que a previsão das normas com políticas públicas e sociais, perfazem-se em normas de eficácia limitada programática vinculando-se aos já mencionados direitos de segunda geração e reivindicando uma atuação eficaz e direta da Administração Pública e das empresas privadas ao oportunizar o acesso a serviços e informações aos cidadãos, como ferramenta de controle da prestação de contas do governo e da participação democrática.

Em vista disso, a efetividade constitucional permite uma redução da arbitrariedade do administrador público, outorgando as diretrizes internalizadas pelos ordenamentos que formam esse microssistema anticorrupção a finalidade de estabelecer um controle interno em conjunto com a boa governança, tendo como base o programa de Compliance Anticorrupção de forma a 
complementar as diretrizes das Estatais e englobando a participação e o comprometimento das autoridades superiores do governo para evidenciar um nítido e inequívoco apoio ao programa.

Dessa forma, com o objetivo de buscar essa efetividade a que nos referimos alhures e termos, de fato, um sistema íntegro de gestão que reflita na Boa Governança e na observância do movimento constitucional atual, surgiram uma série de normas infraconstitucionais inspiradas em modelos estrangeiros.

Ocorre que de nada adianta termos leis inspiradas nos modelos mais rígidos do mundo, sem que haja uma efetiva modificação cultural e institucional dos envolvidos, seja na esfera pública ou privada. Significa dizer que a Administração Pública, especialmente a Direta (entes federativos), deve estar imbuída no sentido de ser pioneira quando na implementação dos referidos sistemas e engendrar todos os esforços possíveis para compor da melhor forma sua estrutura operacional. Afinal, para que se tenha o tipo penal relativo à corrupção, faz-se necessária a participação de um agente público. Nesse sentido, andou bem o Ministério da Transparência e Controladoria-Geral da União (CGU) que, por meio da Portaria n. 57/19 alterou a Portaria n. 1.089/18 que regulamentou os Programas de Integridade do Governo Federal e concedeu novo prazo para criação de programas anticorrupção nos órgãos federais.

Neste mesmo sentido, é louvável a atuação deste mesmo órgão na regulamentação de procedimentos relativos ao acesso e tratamento de documentos e informações eletrônicos, por meio da Portaria n. 1.335/2018, como o estabelecimento de procedimentos para acesso e utilização do Portal do Observatório da Despesa Pública, evidenciando a regulamentação e o estabelecimento em conjunto com as ferramentas de otimização para uma maior transparência e efetividade, pilares de uma boa governança.

Diante de todo esse complexo contexto, espera-se de maneira bastante otimista, que todos os Poderes da República e, especialmente os novos governantes, estejam, de fato, comprometidos no exercício digno dos mandatos que lhe foram outorgados com o objetivo de administrar a coisa pública de uma forma eficiente e capaz. Afinal, a sociedade exige medidas mais eficazes no combate à corrupção, tornando-se em razão do descaso do gestor público e privado, intolerante e meticulosa quando se trata do descaso com os recursos públicos e, sobretudo, com os direitos fundamentais assegurados na Constituição. 


\section{REFERÊNCIAS BIBLIOGRÁFICAS}

BARROSO, Luiz Roberto. Interpretação e Aplicação da Constituição, São Paulo: Renovar, 2013.

CARBONELL, Miguel e JARAMILLO, Leonardo Garcia. El Canon Neoconstitucional. Madri: Editora Trota. 2010.

CARNEIRO, Claudio. Neoconstitucionalismo e Austeridade Fiscal: confronto constitucionalhermenêutico das cortes constitucionais do Brasil e de Portugal. Salvador: Juspodivm. 2017.

. Compliance e Boa Governança (Pública e Privada). Belo Horizonte: Juruá. 2018.

SUNSTEIN, Cass; HOLMES, Stephen. The cost of rights: why liberty depends on taxes. Nova Iorque: W.W. Norton \& Company, 1999.

Instituto Brasileiro de Governança Corporativa - IBGC. Código das melhores práticas de governança corporativa. 4.ed. / Instituto Brasileiro de Governança Corporativa. São Paulo, SP: IBGC, 2009. 73 p. Disponível em: Acesso em: 10 janeiro de 2019.

SARMENTO, Daniel. Filosofia e Teoria Constitucional Contemporânea. Rio de Janeiro: Lumen Juris, 2009.

STRECK, Lenio Luiz. Verdade e Consenso. Constituição Hermenêutica e Teorias Discursivas. Da possibilidade à necessidade de respostas corretas em Direito. Rio de Janeiro: Lumen Juris. 2009.

Jurisdição Constitucional e Hermenêutica. Uma nova crítica do direito. 2 ed. Rio de Janeiro: Forense. 2014.

Submetido em: 20/04/2019

Aceito em: 23/09/2019 